\title{
Portraying Informal Digital Learning of English from Management, Beliefs, and Practices
}

\author{
Surya Agung Wijaya, ${ }^{*}{ }^{*}$ Abdul Asib, ${ }^{2}$ Suparno Suparno ${ }^{3}$ \\ 1, 2, 3 English Education Department, Faculty of Teacher Training and Education, Universitas \\ Sebelas Maret, JI. Ir. Sutami No.36 A Surakarta 57126, Indonesia
}

*) Corresponding Author

Email: saw.learning@student.uns.ac.id

DOI: $10.18326 /$ rgt.v14i2.157-184

Submission Track:

Received: 01-06-2021

Final Revision: 01-12-2021

Available Online: 05-12-2021

Copyright @ 2021 Author(s)

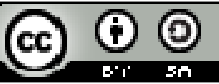

This work is licensed under a Creative Commons Attribution-ShareAlike 4.0 International License.

\begin{abstract}
In a couple of years, massive multiplayer online role-playing games (MMORPGs) and previous works reported various informal digital learning of English (IDLE) activities within and around video games that could enhance student-gamer vocabulary outcomes; receptive and productive language skills; and language socialization. The lack of multidisciplinary literature reviews between IDLE and language policy (LP) allows this study to open discussion on both areas. The urgency of this study is the high adoption of IDLE framework without considering LP where the reason for student engagement from MMORPG activities can be explained. This study aims to portray IDLE practitioner's activities in MMORPG from language management, beliefs, and practices. Following the long-term process, the data were generated from auto-ethnography and photo-elicitation that were taken from in-game and out-of-game activities. This article found three major findings. First, the management of MMORPG provoked gamers to communicate as a part of the game mission, and the guild could potentially develop top-down and bottom-up LP. Second, the value of language in the community played a role in the decision-making language use from the negotiation process. Third, English and Mandarin dominated language practices from different interlocutors in various forms such as language in MMORPG's context, code mixing, and abbreviation from multilingual sides giving various reading texts in contexts. The high status of English is still dominated by out-of-game language practices. There are two major implications in theory and praxis that would be discussed in this study.
\end{abstract}

Keywords: Auto-ethnography; IDLE; language policy; MMORPG; multilingual environment 


\section{INTRODUCTION}

Video games and language learning have gained attention from some scholars working with a console-operated video game (e.g., Leppänen and Piirainen-Marsh (2009) with Final Fantasy) when the Internet was still quite limited in some areas in the world. The massive innovation on MMORPG and personal computer (PC) brought discussion on PC game - World of Warcraft (WoW) - (Li et al., 2014; Zheng et al., 2015); and browser-based games Wonderland and NineRift - (Peterson, 2012a \& 2012b). In a decade, the mobile phone becomes as powerful as PC thanks to the juxtaposed virtual and real world, an augmented reality video game. Pokémon Go has changed the way of playing video games by combining exercise, traveling, and real-world gamer-togamer socialization (Wu, 2019).

With the contribution of MMORPG and language learning on socio-culture, second language acquisition (SLA), linguistic, language learning motivation and anxiety, and cognitive aspect (Lee \& Pass, 2014; Pervolaraki et al., 2015; Peterson, 2016); the endeavor of the real contribution of MMORPG on English language learning is still questionable by some scholars. Some weaknesses still found enacting video games into school curricula, and students faced confusing focus on completing tasks and playing video games (Reinhardt et al., 2014). However, previous work was still limited to in-game activities (as an extracurricular program). Interestingly, playing MMORPG is also considered practicing English in-game and out-of-game activities called MMORPG's information system (Harviainen \& Vesa, 2016).

In current literature, under the umbrella term of IDLE has theoretically been developed and implemented by Lee (2017) and other scholars (e.g., Lee \& Drajati, 2019; Lee \& Dressman, 2017; Lee \& Lee, 2019). However, Lee's IDLE works were still on the macro discussion of MMORPG and were portrayed as a part of the sample of IDLE itself. However, MMORPG provides various IDLE activities (e.g., watching YouTube videos (Li et al., 2014) and reading NPC (NonPlayer Character) dialogs, storylines, updated information, tips, and tricks from video games and communities (Lee \& Pass, 2014). The high status of English in the gaming community has been pushed student-gamers to use English as their identity to be a part of digital citizens (Corredor \& Gaydos, 2014). Therefore, 
monolingual student-gamers could get experience multilingual or bilingual environments.

WoW is reported to give a contribution to gamers' reading skills (see Zheng et al., 2015; Li et al., 2014). They emphasized that gamers' reading activities could not be limited by reading text but semiotic resources such as words, symbols, images, numbers, colors, and sounds from various in-game and out-of-game activities. Moreover, with regards to browser-based games, NineRift, Peterson (2012b) found gamers' reading and writing skills are a means of socialization among gamers from a discourse perspective. Social context played an important role in the conversation with various interlocutors. Providing anonymity with pseudonyms and avatars could potentially decline anxiety; so gamer-to-gamer communication gives the opportunity to take risks enabling communicative competence in L2 and cross-cultural communication (Anderson, 2019; Lee, 2019a; Peterson, 2012a). Moreover, MMORPG provides various interactions including gamer-to-NPC, gamer-to-game, and gamer-togamer (Jabbari \& Eslami, 2018). Where discussions on Spolsky's LP have absented from IDLE, the current studies on LP and L2 learning are mostly taken in-class activities.

Spolsky's (2004) LP model has been adopted by some scholars in different areas, for example, family LP (Gharibi \& Seals, 2019), academic LP (Cots et al., 2014), and LP on English as medium of instruction (EMI) (Chen, 2019; Hu \& Lei, 2013; Rahman et al., 2019). Hu and Lei (2013) and Rahman et al. (2019) found that language management was still on the level of preliminary level. English was not implemented in the level of language practices because students believed that they needed to draw their L2 knowledge in L1. It indicated that the admission for L2 was far from the standard of EMI. Therefore, students and teachers decided to use L1 more dominant for comprehension purposes although there was English only policy in the class. In contrast, research learning beyond the classroom reported how students take to use L2 for their IDLE purposes.

The needs for discussion on interweaving LP and IDLE activities in MMORPG urge this study to implement Spolsky's model. Therefore, this study is to explore language management, beliefs, and practices on MMORPG's 
information system (Harviainen \& Vesa, 2016). Moreover, this study potentially capture gamer's English language development - reading and writing - that appears in-game (top-down language planning from developer and guild: language options, storylines, NPCs, working in a group, etc.) and out-of-game (bottom-up fandom supports: collecting and sharing additional information, practicing code-mixing, hybrid version, and abbreviated language in private and group chat, or blog) activities that operate student-gamer beliefs to the language choices and practices.

\section{Roles of Spolsky's Language Policy Portraying IDLE in MMORPG Community}

MMORPG provides some significant features including (1) virtual worlds based on a theme or a narrative, (2) a text or voice chat; (3) controlled avatars, goal-based communication environment; (4) customizing many aspects of the game (modding), and (5) membership of a game-based social group (Peterson, 2012a, p. 363). IDLE has been highlighted into receptive IDLE activities (RIA) including (e.g., reading storyline and NPC, watching YouTube channel or Discord about video games) and productive IDLE activities (PIA) including (e.g., interacting with guild members in-game chat and using third-party apps to share information with other gamers) (Lee \& Drajati, 2019; Harviainen \& Vesa, 2016). This concept is also known as "game-enhanced" using a commercial game that does not design for learning "vernacular" that incidentally gives beneficial second language (L2) practices in the classroom (Reinhardt \& Sykes, 2014). However, language practices in MMORPG were dominated by code mixing, linguistic form, bilingual cultural codes, hybrid codes, English-based abbreviation, and borrowing English-based expression for gaming-specific terms (Corredor \& Gaydos, 2014; Lee \& Pass, 2014; Li et al., 2014). Therefore, MMORPG studies mostly reported in the areas of cognitive SLA (Lee, 2020; Li et al., 2014; Zheng et al., 2015) and sociocultural SLA (Colby, 2021; Corredor \& Gaydos, 2014; Peterson, 2012a \& 2012b; Przymus et al., 2020). MMORPG is clustered into three main potential language learning activities called "MMORPG's information system" (Harviainen \& Vesa, 2016, p.202-204).

As the conceptual parameters of this work, Spolsky (2004) points out that LP can be distinguished into three components including language manage- 
ment, beliefs, and practices. Although they have independent components, Spolsky (2004, 2009, \& 2012) acknowledges those areas are interrelated. Moreover, Spolsky (2009) acknowledges that his theory could also be implemented in other areas - religious community, business, linguistic landscape, legal and health institutions, government, and activist groups including MMORPG's community. Langauge management is provided in the MMORPG features that purposely attempt to modify language beliefs and practices of games (Spolsky, 2004). Moreover, English as the majority language practices and the most valuable language learning "in the wild" (Reinhardt \& Sykes, 2014) is believed by gamers that could give beneficial of their gaming practices. When gamers have a positive attitude toward English, they potentially have a willingness to communicate in English with MMORPG community practices (Lee, 2019a; Lee \& Drajati, 2019).

Table 1

MMORPG's Information System

\begin{tabular}{llll}
\hline & Retrieval core & $\begin{array}{l}\text { Social } \\
\text { information } \\
\text { system }\end{array}$ & $\begin{array}{l}\text { Player } \\
\text { produce } \\
\text { material }\end{array}$ \\
\hline $\begin{array}{llll}\text { Information } \\
\text { forms }\end{array}$ & $\begin{array}{l}\text { Information-supplying } \\
\text { system }\end{array}$ & $\begin{array}{l}\text { Players' } \\
\text { interactions }\end{array}$ & $\begin{array}{l}\text { Authentic } \\
\text { materials }\end{array}$ \\
& NPCs & Chatroom/talk & Fan fiction \\
& Avatars/characters/monsters & Guilds & Wikis \\
& Items/Weapons & Party (doing & Blogs \\
& Skills & quest in a group) & YouTube \\
& & & videos \\
& & & Guild social \\
& & & media \\
groups \\
Third-party \\
\end{tabular}

Moreover, the MMORPG community could build their own LP where it is seemingly developed between MMORPG's system information and social interaction, in which game-to-gamer (in the guild) could develop their own 
rules to achieve gaming goals. Interestingly, Sykes et al. (2010) emphasized that there are three goals - game-driven, user-driven, and contextual goals - of gamers. Virtual identity has been developed by sharing information, exchanging items, practicing together, and negotiating strategies (Harviainen \& Vesa, 2016; \& Sykes et al., 2010). Leppänen and Piirainen-Marsh (2009) pointed out that gamer-to-gamer language practices recycling and modifying from language provided by retrieval core are shaped by and shaping overt language policy. Moreover, they also mentioned out-of-game activity in fan fiction developing informal LP. Therefore, when we see the position of LP and IDLE, it could portray by juxtaposing LP, IDLE, and MMORPG theories from interdisciplinary discussions.

Table 2

Theoretical Implementation of Spolsky's Language Policy in IDLE

\begin{tabular}{lll}
\hline Spolsky's Language Policy & $\begin{array}{l}\text { Benson's Four Dimension } \\
\text { of extramural IDLE }\end{array}$ & $\begin{array}{l}\text { Harviainen \& Vesa's } \\
\text { MMORPG }\end{array}$ \\
\hline $\begin{array}{l}\text { Management: any (explicit } \\
\text { or implicit) intervention }\end{array}$ & $\begin{array}{l}\text { Formality: unstructured } \\
\text { and no certification }\end{array}$ & $\begin{array}{l}\text { Retrieval core } \\
\text { Social information } \\
\text { system } \\
\text { Player produce } \\
\text { material }\end{array}$ \\
$\begin{array}{l}\text { Beliefs: value of language } \\
\text { and language use }\end{array}$ & $\begin{array}{l}\text { Pedagogy: Naturalistic } \\
\text { Locus of control: Self- } \\
\text { directed }\end{array}$ & - \\
$\begin{array}{l}\text { Practices: language and } \\
\text { language use }\end{array}$ & Location: out-of-class & $\begin{array}{l}\text { In-game and out-of- } \\
\text { game }\end{array}$ \\
\hline
\end{tabular}

Rooted from Benson (2011), Benson and Chik (2011) portray video games from formality, pedagogy, locus of control, and location. First, the management from "formality" emphasizes that language learning in MMORPG is not the main purpose. Implicitly, from providing enjoyment during the gameplay, knowledge of English is used to improve character development by collecting information. The developer already sets up the language choices where English as a lingua franca is provided with implicit and explicit LP targeting the global market. Second, the values of language and language use 
are represented by "pedagogy" and "locus-of-control". Implying public pedagogy in IDLE, the absence of direct English language instruction indicates incidental language development from players' created materials and expertplayers explanation. Moreover, "locus-of-control" plays an important aspect in players' decisions whether which language is used or with whom language is practiced. Third, the affordances of L2 in MMORPG also depend on in-game and out-of-game "location", for example, real-world location (e.g., internet café, at home, game centers, etc.), devices, and server (e.g. USA, UK, or ASIA) are crucially related to the language practices with interlocutors. Therefore, LP may appear explicit or implicit related to how language is managed by policymakers and their belief system meeting how grassroots support or deny the LP and practice the language considering the value of the language (Spolsky, 2004). It could not simply see from top-down and bottom-up supports. Little research on the relationship between LP and IDLE could potentially help teachers who want to enact MMORPG in the classroom where this research comes with two research questions.

1. What are the underlying factors of language management in MMORPG?

2. How do different language practices in-game and out-of-game MMORPG affect language beliefs in the IDLE activities?

\section{RESEARCH METHODS}

The data were taken from a guild in MMORPG called "Sword Art Online: Memory Defrag" (SAO MD) and the guild's WhatsApp group established on October $7^{\text {th }}, 2017$. The commander and vice commander recruited the members in the guild to join the WhatsApp group during quests in the MMORPG app, and members freely chose to become a member or not. There are nine members in the WhatsApp group from ten guild members. One of the researchers, the first author, became an insider in this research due to gaining access from gatekeepers and experiencing MMORPG. One of our team has played this game for almost two years moving from one guild to another until he decided to stay in this guild for almost one year and got permission. The guild members come from different countries such as Malaysia, Singapore, Hong Kong, and Indonesia. SAO 
MD has two versions of the game, the Japan version and the global version of SAO MD. The data are taken from global where the language options are English, Korean, and Chinese with dominated Japanese voice over making English with a Japanese accent also known as "Wasei Eigo." On the other hand, the original video game, Japanese version, only provides the Japanese language with some English expressions (e.g., loading). Therefore, games around the world have only three options in the global version. For non-Korean and Chinese speakers, the only available language is English.

Regarding profiles from our team, the first author is a graduate student from a bilingual classroom. However, he has a little opportunity to practice intercultural communication in the English major. Most of his classmates are local students with lack of overseas experience. When he joined the current guild, he faced various interlocutors and cultures. His mother tongue is Javanese, Bahasa Indonesia as second language (L2), and English as foreign language (with more than 500 TOEFL scores). The data are taken from two places, SAO MD with two hours season per week and WhatsApp group from 26 ${ }^{\text {th }}$ August, $2019-31^{\text {st }}$ December, 2020.

Table 3

Language Practices in WhatsApp Messages

\begin{tabular}{lllllll}
\hline Status & Guild members & Level & English & $\begin{array}{l}\text { Code } \\
\text { mixing }\end{array}$ & Mandarin & $\begin{array}{l}\text { Total } \\
\text { messages }\end{array}$ \\
\hline Veteran & Commander & $180-199$ & 221 & 5 & 2 & 228 \\
Veteran & Vice commander & $206-245$ & 2237 & 29 & 37 & 2.303 \\
Veteran & Member 1 & $178-195$ & 1183 & 6 & 1 & 1.190 \\
Veteran & Member 2 & $150-168$ & 470 & 6 & 8 & 484 \\
Freeloader & Member 3 & $103-179$ & 11 & - & 32 & 43 \\
Veteran & Member 4 & $147-180$ & 505 & 1 & - & 506 \\
Newbie & Member 5 & $87-$ out & 127 & - & 24 & 151 \\
- & Member 6 & - & - & - & - & 0 \\
Veteran & Researcher & $128-155$ & 279 & - & - & 279 \\
& Total & & 5033 & 47 & 104 & 5184 \\
& Percentage & & $(97 \%)$ & $(1 \%)$ & $(2 \%)$ & $(100 \%)$ \\
\hline
\end{tabular}

The MMORPG data were approached by a ludo-narrative model (Toh, 2015 \& 2019). The data were taken from three layers such as (a) screenshots from retrieval core, (b) screenshots from gameplay interactions, and (c) 
transcripts and screenshots from guild WhatsApp group interactions. The conversation in the SAO MD app is a tad difficult to be traced back and can only be captured by screenshots. Due to private and public Internet data and to protect participants, the data are collected from the auto-ethnographic considered to portray "personal experience to examine and/or critique as a cultural experience" (Jones et al., 2013, p.22) to take language management and practices, and photo elicitation (Harper, 2002) to take language beliefs. The data of SAO MD were collected by classifying through retrieval core and social information system (Harviainen \& Vesa, 2016) by screenshotting 251 images. As player produce material, the data from WhatsApp are screen-shot, transcribed, and translated from Mandarin to Indonesia with translator help followed by translating into English with the team. Practicing photo elicitation by using screenshots, two other members of the research became interviewers asking about language beliefs where the questions were adopted and modified based on the context of MMORPG (Jeoffrion et al., 2014; Chen, 2019). To analyze the data in CALL context, the multimodal analysis (Valencia, 2015, p.4) is used including four steps: (1) examining the relationship among the multifarious modes of communication, (2) establishing semiotic clusters to map out multimodal design in MMORPG, (3) focusing on modes of communication as units of analysis, and (4) establishing intersemiotic relationships among modes conjoined to create specific meaning.

\section{FINDINGS AND DISCUSSIONS}

\section{Language Management within and Around MMORPG}

Spolsky's (2004) work clearly defines language management as "any specific efforts to modify or influence that practice by any kind of language intervention, planning, or management" (p.5). As a point of departure to see LP in the MMORPG community, he also adds that language management is not always explicit, but also implicit and comes from the language beliefs and practices of community members within and around the game. Retrieval core provides various multimodalities - texts, images, symbols, numerals, sounds, movement, colors, icons, etc. - in MMORPG where gamers could make decisions based on habitual literacy activities (Toh, 2019). One of the most important 
reading activities in MMORPG is to comprehend information within games to achieve the rewards due to developing each gamer's account.

\section{Figure 1}

"Say Something in Chat" under the Policy

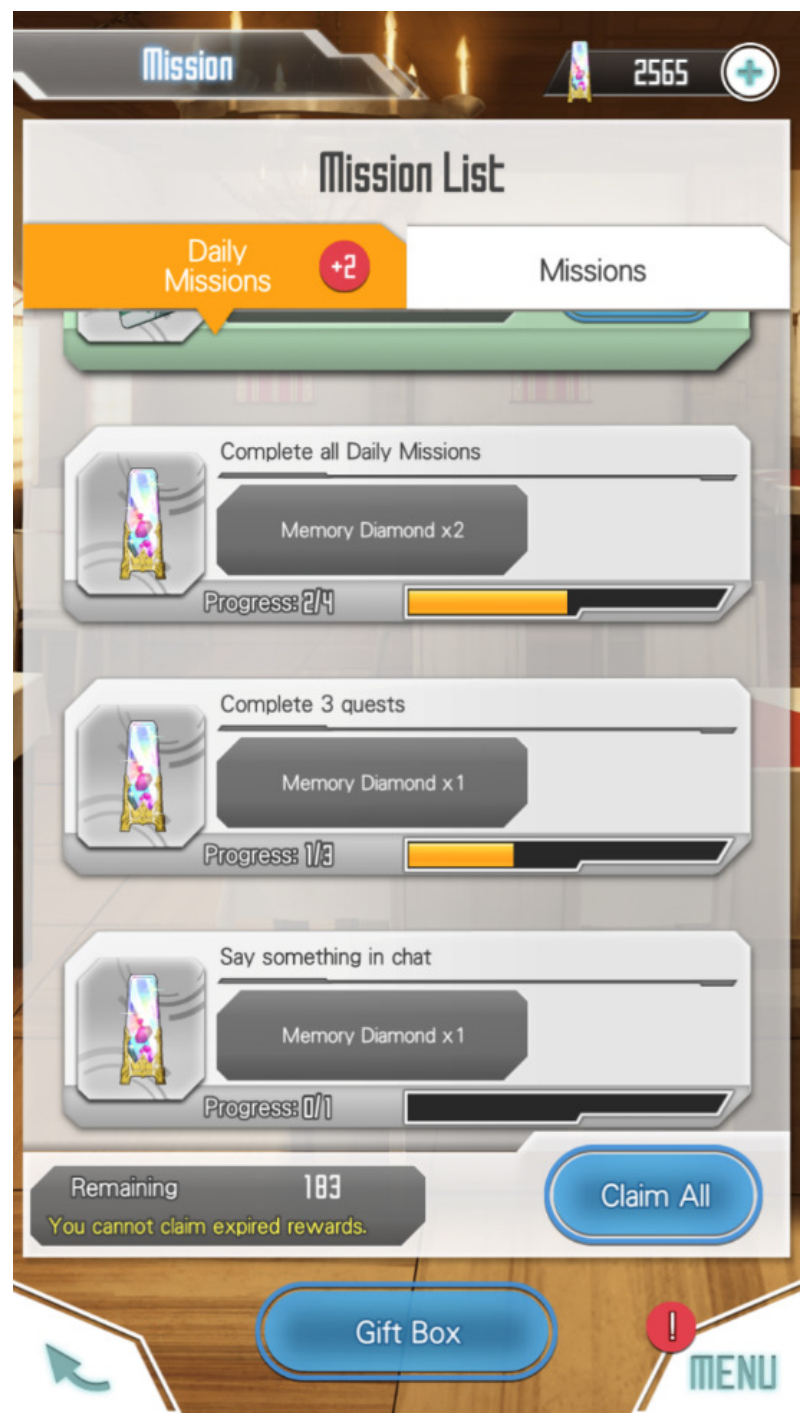


As a mobile video game, information is displayed in vertical order for touching experiences. English as a language option is also translated into visual to help gamers engaging information given by retrieval core. In line with a previous study, Li et al. (2014) found reading activities in MMORPG dominated by "decoding texts, symbols, and numbers" (p. 139-140). Moreover, this game explicitly allows gamers to socialize with other gamers where language practices have various languages (multilingual settings). Gamers could not accomplish all daily missions without "say something in chat." Diamond cubes, rewards, are set up to trigger gamer-to-gamer socialization with no explicit intervention of various language uses although the game also restricts the language practice (see Figure. 4). By pushing gamers to socialize, language practices are provoked to meet various language interlocutors. However, by standardization process, three official languages of this MMORPG played as language communication options to have a "global" profile.

Furthermore, Spolsky (2004) points out various interventions that are potentially given by "person" or "group." Retrieval core also provides guild system or social in-game environment for gamer-to-gamer work in a group (e.g., quests could only be finished by synchronous works with only guild members to achieve the rewards) due to character development. Moreover, in the guild, members are clustered into three categories - newbie, freeloader, and core members - where they could negotiate to contribute to the guild although communication among them was found in different ways (Ang \& Zaphiris, 2010). They noted that core members, experienced players, highly spent and contributed to the guild for a very long time. They could potentially build the LP for guild purposes where they mostly helped "newbie" known as new member with the low-level player and "freeloader" recognized as a member with the high-level player without feeling belonging in the guild. Therefore, language use is needed to be established by core members to communicate and accumulate various needs from different interlocutors in a multilingual context.

This study found that gamers could potentially build their own new social rule systems juxtaposed from retrieval system information or a totally different system. In this guild, the written document has been made in Mandarin followed by English although it does not explicitly regulate the language used in 
the guild. Moreover, language practices in this guild were dominated by English and Mandarin (see Table. 3). The guild system gives a chance for gamers editable only for the commander and vice commander - to write in the notification board that pops up when the avatar moves around the guild flag. Top-down LP made by the commander or vice commander intentionally concealed gamer-to-gamer language use in the guild. Moreover, MMORPG is dominated by synchronous activities and clock-driven time (Harviainen \& Vesa, 2016) where the word "UTC" has been adopted from retrieval core to mediate different time zones of gamers. Therefore, this guild expected Mandarin speakers that would consider at the first place as language practices and English as the second one.

\section{Figure 2}

\section{Guild System and Policy}

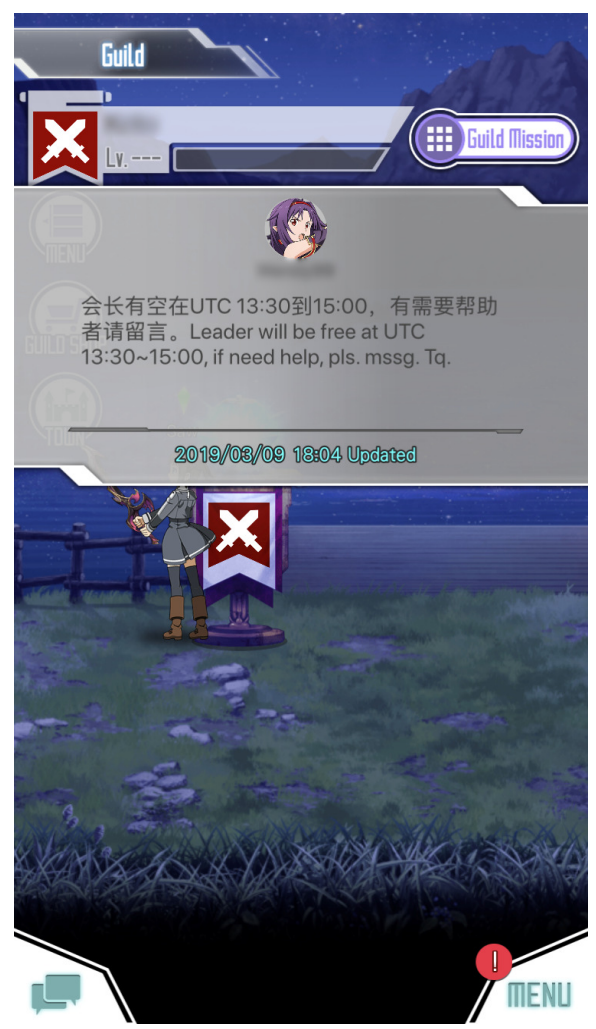


On top of that, Corredor and Gaydos (2014), Li et al. (2014), and Pervolaraki et al. (2015) acknowledge that gamers become digitally literate from MMORPG activities (e.g., problem-solving, socializing, information seeking, and strategizing) where most of them required reading skills for (e.g., announcements; storylines; name of characters, weapons, special skills of character, and items; term conditions; and menu options). Therefore, L2 language learning becomes a fundamental asset to receive and share information. By having guild in MMORPG, it comes to the notion that language management intervenes "learning the language to play the game" (Sykes et al., 2010, p.129).

\section{Language beliefs about IDLE practices in MMORPG}

Representing language beliefs in IDLE practices, Spolsky (2004, p.5) points out "its language beliefs or ideology - the beliefs about language and language use." High exposure and value of English in MMORPG are the catalyst of ingame and out-of-game PIA and RIA (Lee, 2019b \& 2020). Moreover, MMORPG environments within and around the game also found intervening players to study L2 to fully access information and get advantages for their account developments. One of the significant social values of mastering English is gamers getting access to better resources in multilingual contexts (Corredor \& Gaydos, 2014). This research found gamers could not only rely on English skills; "social skill" is also not the one in multilingual contexts and intercultural communication (Pervolaraki et al., 2015).

With red background, it shows an identical color with Chinese emblems. The second layer of the background is the ornament of golden-brown leaves. It represents the color of the sun that has a shorter appearance on the earth compared to other days. Also provided is visual text with Tangyuan known as glutinous rice with pink, green, and white colors combined in one bowl meaning togetherness. On top of that, white font gives contrast to the background layers, languages are adjusted from English, Mandarin, and Bahasa Indonesia. English on the top portrays a representation of lexical items from Mandarin although players who do not understand Mandarin still could get the meaning making from English and visual text. In the middle as the nucleus, giving benediction in Mandarin brings deeper information from the event. Where 多福多寿身体健康 
祝你全家 has no translation in English and Bahasa Indonesia in the picture, it hopes readers have blessings and health with whole family members. Written and visual texts are combined to help international readers meaning making from the information given. However, Bahasa Indonesia is placed on the bottom representing lower status on the global citizen. Making communication among various interlocutors easier, translanguaging practices saw as a means of negotiation in meta-game and intra-game discourse (Colby, 2021; Przymus et al., 2020; Przymus \& Smith, 2017).

Figure 3

Facing Intercultural Communication Competence

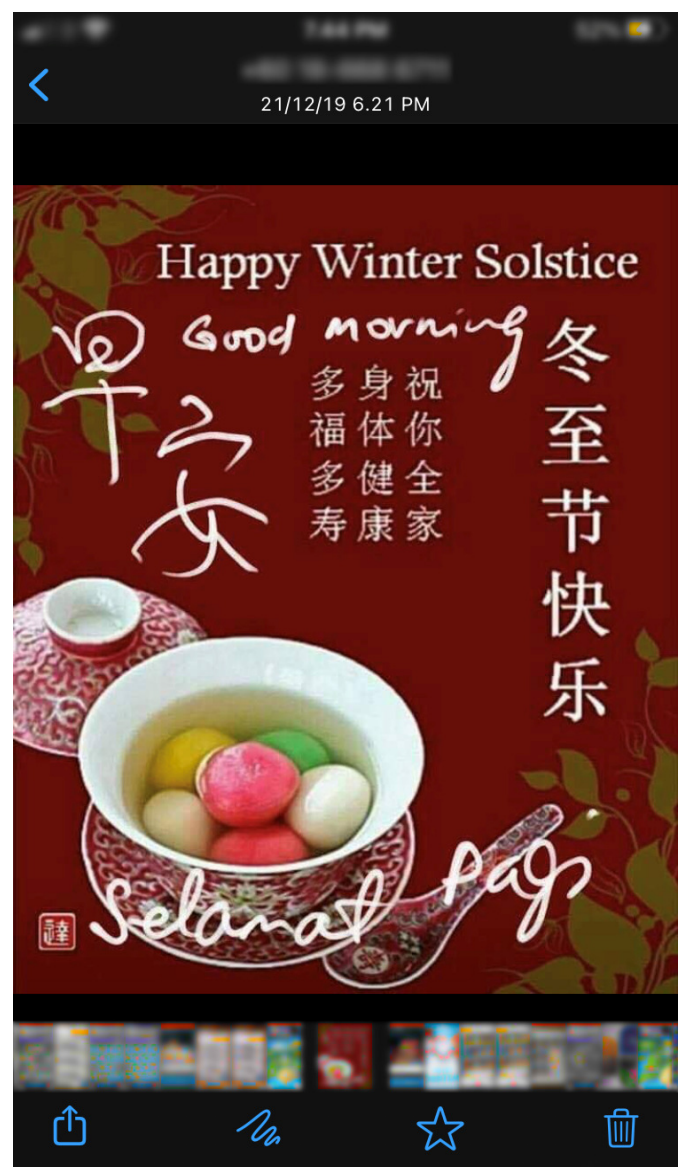


The status of the researcher's indigenous or national language in global communication is not strong enough within the community members (see Table. 3). Other gamers are also underperforming their indigenous or national language in the community where the guild consists of various interlocutors. Catalyzing, the researcher communicated in the target language over his indigenous or national language. From the mental processes, the practice of IDLE was seen and believed as "save language" among other languages to reduce guild conflict. Familiarity with community used specific technical English vocabulary, colloquial English expression, terms for gaming, negation process, and promoting culture to cultivate personal relationships with guild members (Lee, 2019a, 2020; Lee \& Dressman, 2017). The researchers have witnessed the fact that the high status of English in WhatsApp group chat is not enough for covering L2 language learning in classroom needs. However, IDLE is seen as an asset for gamers to have access to a multilingual community to practice L2 language learning (Corredor \& Gaydos, 2014). For instance, on August 9, 2019, member 3 announced that he retired from game activities because he took an English course. However, he still wanted to stay in the ingame and out-of-game guild. He wished that he could come back during his English course. However, he has become a silent reader in the WhatsApp group since that day. Previously, IDLE was reported directly to have a contribution to language learning in the classroom (Lee, 2017, 2019; Lee \& Drajati, 2019; Lee \& Dressman, 2017; Lee \& Lee, 2019), this research expands classroom L2 learning as a provision coming to IDLE and various IDLE strengthening other IDLE activities.

\section{Table 4}

Language Beliefs in Multilingual Environment

$\begin{array}{ll}\begin{array}{l}\text { The second } \\ \text { author }\end{array} & \begin{array}{l}\text { When your friend sent this picture to celebrate "Happy } \\ \text { Winter Solstice" that you never celebrate before, what is } \\ \text { your opinion about people who speak several languages } \\ \text { are more capable of adapting to other cultures? }\end{array} \\ \begin{array}{l}\text { The first } \\ \text { author }\end{array} & \begin{array}{l}\text { I felt that way because I saw the figure on the vice } \\ \text { commander that actively communicates with other } \\ \text { members in English and Mandarin. And, this picture is sent }\end{array}\end{array}$


by him... He chats with all members in guild chat in SAO MD talking about the quest, and he also always invites the members who have free time to do guild quest in the WhatsApp group... I feel he could mediate English and Mandarin speakers' needs for guild purposes... Bahasa Indonesia on this picture is important for me that it gives the sign of acceptance in the community.

The second : When you see this picture, what is your opinion statement author said that "knowledge of English is not enough to prepare for intercultural communication?"

The first : I I agree with the statement because I still feel a barrier that I author create to myself in the only Mandarin conversation. English may help me to reduce the gap between me and other cultures in the guild. However, it does not make me brave enough to involve in the conversation with Mandarin only. I just only looked for the meaning on Google Translate to engage the conversation and become silent readers...I think Google translate does not give me the context of the conversation...I wait for other members to replay in English then I will replay...As long as English is present in the conversation, I will join...But, if only Mandarin is used during the gameplay, I will do not understand the direction of the quest and just only wait for English explanation or do nothing.

\section{Language Practices Meeting Gamer-to-Gamer Negotiation}

Spolsky (2004, p.5) emphasizes, "Its language practices - the habitual pattern of selecting among the varieties that make up its linguistic repertoire." Moreover, Spolsky also acknowledges that language practices could not stand alone without considering language management and beliefs. Where the written document on guild showing Mandarin comes first on the top of guild regulation followed by English, the practice showed English dominated the conversation (see Table. 3). Among available languages from various members, English and Mandarin have been chosen as language communication over their national or indigenous language(s) of guild members as a part of the guild's identity. 


\section{Restriction of in-game language use}

The in-game chatroom has been designed with a similar interface with common messages with avatars, messaging icons, and additional information. Language management clearly limits and regulates language practices under "the terms of services" where it restricts language use in the chatroom. In this case, the negotiating process between expert (vice commander) and novice (researcher) gamers appeared before conducting a guild quest in September 2019. An expert gamer explained and helped the term condition of guild quest. Furthermore, previous study reported that the negotiation between them gave shortcut information for novice players rather than exploring, searching, and reading in-game and out-of-game information. Collaboration is used for problem solving of quests that probably could not be finished alone (Li et al., 2014).

\section{Figure 4}

Expert and Novice Gamers

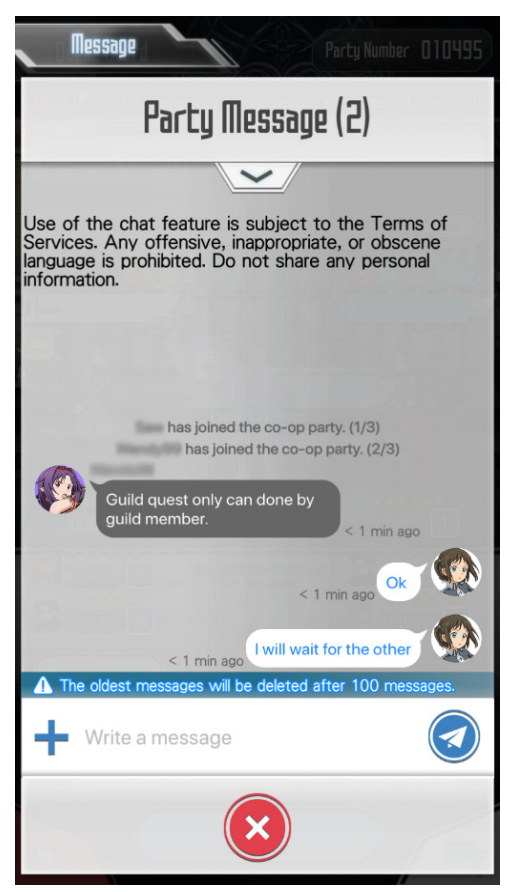




\section{Figure 5}

Short cut for Language Practice

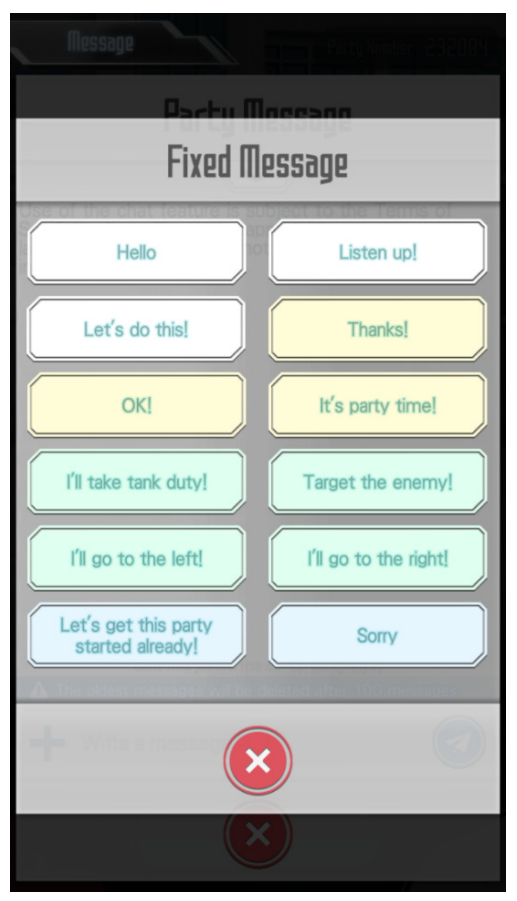

To become a good guild member, players enhance their English communication and gameplay strategies (Lee, 2020). Knowledge of MMORPG from expert gamers helped novice gamers who were not familiar with the guild system. English helps facilitate the gap of knowledge for guild purposes. This mental process helped the researcher learn how to negotiate and practice his English with non-native speakers. However, the language practice was limited by the policy where the MMORPG totally blocks some vocabulary related to "offensive, inappropriate, and obscene languages." Interestingly, gamers could not express anger or naughty stuff, but MMORPG played a double standard by giving 18+ content in the characters and voiceover. Furthermore, "Do not share any personal information" is more optional as a warning. The researcher witnessed the fact that he could still send his phone number to join the WhatsApp group from the in-game chatroom. Standardized and accepting 
official languages, it restricted other languages. In-game artificial intelligence could tackle indigenous languages assuming as offensive, inappropriate, and obscene languages. In addition, retrieval core is supported by adding short instant messages by touching (+) button from (see Figure. 5) called "fixed massage". Those messages are automatically be translated into Korea or Mandarin depending on the game language default.

\section{Player produce material reducing MMORPG restriction}

Guild offered third-party app over in-game chatrooms because the advantages are uncovered in-game futures such as notification, various media (e.g., video, voice notes, pictures, etc.), tagging friends (@name), and tracing back conversations. Mediating for synchronous and asynchronous communication, core members gave WhatsApp group space for helping, asking for help, sharing new information, and negating guild activities (Ang \& Zaphiris, 2010). Moreover, non-standard English can be practiced with less policy. Where negotiating process can be done before and after the quest, they finished one quest followed by offering a new quest.

\section{Tabel 5}

Negotiation Process on Player Produce Material

[10:26 PM, 6/7/2020] Vice commander: Ok. Who host?

[10:26 PM, 6/7/2020] Member 1: U?

[10:26 PM, 6/7/2020] Vice commander: Ok.

[10:27 PM, 6/7/2020] Member 1: Cuz I dunno which boss XD

[10:39 PM, 6/7/2020] Member 1: Done?

[10:40 PM, 6/7/2020] Vice commander: Done for guild quest.

[10:40 PM, 6/7/2020] Commander: Ok

[10:41 PM, 6/7/2020] Vice commander: Wanna spam for treasure or just call it a day?

[10:41 PM, 6/7/2020] Member 1: Let's end it here for tonight

[10:41 PM, 6/7/2020] Vice commander: Ok. Thank you for parties.:-)

[10:41 PM, 6/7/2020] Member 1: I need to spam my SAO AR eventXD

[10:41 PM, 6/7/2020] Member 1: Tyfp

[10:42 PM, 6/7/2020] Commander: Lol

[10:42 PM, 6/7/2020] Commander: Tyfp 
In multilingual contexts in MMORPG, Corredor \& Gaydos (2014) point out code mixing (see Table. 3), hybrid version, and abbreviation language as natural phenomena grounded in the in-game and out-of-game negotiation process. EFL gamers in monolingual environments may not face informal abbreviations, e.g. "cuz, dunno, XD, LOL, and tyfp". Specific vocabulary portrayed their identity as digital citizenship where the written conversation was mostly conducted in informal ways. Negotiating the quest by joking around is mostly used to reduce the intensity and conflict of interest to use guild resources. Gamers also could create an abbreviation for their community; for instance, "tyfp" or "thank you for party" used in context fining the party and expressing gratitude. Learning the English language that is borrowed by MMORPG (e.g., host, party, parry, etc.) and accepted by the community (e.g., mitigator for reducing incoming damage character) is also important to engage the negotiation process; for instance, "host" means a gamer who leads the quest and invite other non- or guild members to join the "party" where collaboration could only fit with three members.

From language practices, it shows how status, acquisition, corpus, and attitude planning from MMORPG are accepted and operated by the speech community. Moreover, the guild members build their own speech community. Therefore, this study suggests similar results from previous studies (Corredor \& Gaydos, 2014; Lee, 2019a \& 2020; Lee \& Dressman, 2017; Li et al., 2014; Zheng et al., 2015). However, this study extends that there are policies from retrieval core, guild, or community members intervening in in-game and out-ofgame language practices, and the policy itself is not standalone but also grown up from bottom-up practices.

\section{CONCLUSION}

Inasmuch as Spolsky $(2004,2009,2012)$ points out in his work, three components portraying LP in MMORPG indicates language management (e.g., the high status of English in MMORPG has been promoted by retrieval core and social system), language beliefs (e.g., only English skill is not enough to cover intercultural communication in guild's multilingual context), and language practices (e.g., reading and writing English are mostly conducted within and around game used for the language of information, communication, and 
negotiation optioning in MMORPG and guild). Therefore, this study attempts to answer two research questions.

The first question is about the underlying factors of language management in MMORPG. There are two majors - top-down and bottom-up - underlying factors of language management in MMORPG. As seen in the top-down policy, intervention comes from a retrieval core and socialization in the guild. MMORPG wants to create a positive environment, so some language practices are limited by the retrieval core due to gamers' protection. Moreover, the topdown policy is not crystal clear from only policymakers, but guild's LP can come from the language available and accepted by community members, bottom-up vectors. The policy could be explicit and implicit from the guild's name, terms, and notifications event out-of-game language practices. Language practices under MMORPG's servers are also considered as language options given by retrieval core (e.g., Japan server with only Japan, and global server with English, Mandarin, and Korea). Therefore, practicing MMORPG as extramural or extracurricular IDLE should consider the language management and each character because the MMORPG information system would not automatically help students in the English language development (Lee, 2017; Benson, 2011).

The second research question focuses on how different language practices in-game and out-of-game MMORPG affect language beliefs in the IDLE activities. Most in-game and out-of-game IDLE activities are dominated by reading and writing activities (Zheng et al., 2015; \& Li et al., 2014). Various genre-reading opportunities could be found such as procedure text from MMORPG instruction, mission, and policy; descriptive text from guild's regulation; and persuasive text from some MMORPG regulation of language practices. Moreover, in the guild chatroom, the conversations also indicate a hybrid text. Those reading opportunities also require classroom knowledge of English and unfamiliar words or languages with a digital dictionary (Zheng et al., 2015). However, in-game language practices are limited; so out-of-game language practices give opportunities to expand the activities. Guild group chat on the third-party app gave opportunities to read and write spoken, written, visual, multimodal texts including video, picture, emoji, and symbol. In multilingual contexts, players' agency plays on language use and choice to access resources 
in the guild. Furthermore, the high status of English was found as a catalyst for players to stay and play video games although IDLE could not cover English language skill needs for classroom emphasizing structuralist and accuracy language practices. Language in the wild is more giving opportunities for language learning in context with various community discourses. IDLE needs classroom English language skills to comprehend the information although it is not enough to give social skills in multilingual contexts where languages are mostly practiced in hybrid, abbreviation, and code mixing. The findings also suggest that language educators, as co-collaborator of IDLE, could support language students by coming to popular MMORPGs among students to observe and explain how to use video games as supplementary inputs of L2.

Although this study was conducted in a long period from a novice into an expert player, this study is far from generalization and transferability to the MMORPG case in general. However, it still portrays a representation of IDLE practices on MMORPG where they use various resources in-game and out-ofgame. Therefore, future studies could be expanded with more participants with various mobile MMORPGs. Theoretical implication indicates Spolsky's LP can be applied in IDLE practices. However, it is restricted to PIA's community (e.g., private and public groups in social media and gamer community). Moreover, the praxis implication shows a great promise on language learning development, especially reading and writing in a context. Gamers are required to train their intercultural communication skill, critical thinking, and negotiating where they can be shaped in the long process grounded in-game and out-ofgame activities. Importantly, this study demonstrates that language-learning development cannot be shaped and developed automatically by joining the IDLE community, but it requires support from knowledge of L2 learning in the classroom.

\section{Declaration of Conflict Interest}

The authors declared that there is no potential conflict.

\section{Acknowledgement}

The researchers would like to acknowledge Lembaga Pengelola Dana Pendidikan (LPDP) Indonesia for their supports and grant given in the 
following financial support for the researchers, authorships, and/ or publication of this research.[rgt]

\section{REFERENCES}

Anderson, S. L. (2019). Crafting Courses as Game Spaces: Examining Video Games Classes in Communication. Communication Studies, 70(3), 277-294. https://doi.org/10.1080/10510974.2018.1539022

Ang, C. S., \& Zaphiris, P.,(2010) Social roles of players in MMORPG guilds. Information, Communication \& Society, 13(4), 592-614. https://doi.org/10.1080/13691180903266952

Baldry, A., \& Thibault, P.J. (2006). Multimodal transcription and text analysis. Equinox Pub.

Benson, P. (2011). Language learning and teaching beyond the classroom: An introduction to the field. In P. Benson \& H. Reinders (Ed.), Beyond the language classroom: The theory and practice of informed language learning and teaching (pp. 7-16). Palgrave Macmillan.

Benson, P., \& Chik, A. (2011). Towards a more naturalistic CALL: Video gaming and language learning. International Journal of Computer-Assisted Language Learning and Teaching, 1(3), 1-13. 10.4018/ijcallt.2011070101

Chen, L. (2019). Problematising the English-only policy in EAP: a mixed-methods investigation of Chinese international students' perspective of academic language policy. Journal of Multilingual and Multicultural Development, 41(8), 718-735. https://doi.org/10.1080/01434632.2019.1643355

Colby, R. S. (2021). Using World of Warcraft for translingual practice: Teaching recontextualization strategies. In R. Colby, M. S. Johnson, R. S. Colby (Ed.), The ethic of playing, researching, and teaching games in the writing classroom. Palgrave Macmillan. https://doi.org/10.1007/978-3-030-63311-0_18

Corredor, J. \& Gaydos, M. (2014). Language games: How gaming communities shape second-language literacy. In H. R. Gerber \& S. S. Abrams (Ed.), Bridging literacies with videogames. Sense Publishers.

Cots, J. M., Llurda, E., \& Garrett, P. (2014). Language policies and practices in the internationalisation of higher education on the European margins: an introduction. Journal of Multilingual and Multicultural Development, 35(4), 311-317. https://doi.org/10.1080/01434632.2013.874430 
Gharibi, K., \& Seals, C. (2019). Heritage language policies of the Iranian diaspora in New Zealand. International Multilingual Research Journal, 14(4), 287-303. https://doi.org/10.1080/19313152.2019.1653746

Harper, D. (2002). Talking about pictures: A case for photo elicitation. Visual Studies, 17(1), 13-26. https://doi.org/10.1080/14725860220137345

Harviainen, J. T., \& Vesa, M. (2016). Massively multiplayer online games as information system: Implication for organizational learning. In Kaneda T., Kanegae H., Toyoda Y., and Rizzi P. (Ed.), Simulation and gaming in the network society. Springer.

Hu, G., \& Lei, J. (2014). English-medium instruction in Chinese higher education: A case study. High Educ, 67, 551-567. https://doi.org/10.1007/s10734-0139661-5

Jabbari, N. \& Eslami, Z. R. (2018). Second language learning in the context of massively multiplayer online game: A scoping review. ReCall, 31(1), 92-113, https://doi.org/10.1017/S0958344018000058

Jeoffrion, C., Marcouyeus, A., Starkey-Perret, R., Narcy-Combes, M., \& Birkan, I. (2014). From multilingualism to plurilingualism: University students' beliefs about language learning in a monolingual context. Language, Culture and Curriculum, 27(1), 8-26. https://doi.org/10.1080/07908318.2014.887724

Jones, S.H., Adam, T.E., \& Ellis, C. (2013). Introduction: Coming to know autoethnography as more than a method. In S. H. Jones, T.E. Adam, \& C. Ellis (Ed.). Handbook of autoethnography (pp. 17-47). Left Coast Press.

Lee, J. S. (2017). Informal digital learning of English and second language vocabulary outcomes: Can quantity conquer quality?. British Journal of Education Technology, 50(2), 1-12. https://doi.org/10.1111/bjet.12599

Lee, J. S. (2019a). EFL students' views of willingness to communicate in the extramural digital context. Computer Assisted Language Learning, 32(7), 692-712. https://doi.org/10.1080/09588221.2018.1535509

Lee, J. S. (2019b). Informal digital learning of English and strategic competence for cross-cultural communication: Perception of varieties of English as a mediator. ReCALL. 32(1), 47-62. https://doi.org/10.1017/S0958344019000181

Lee, J. S. (2020). An Emerging Path to English in Korea. In M. Dressman and R.W. Sadler (Ed.), The Handbook of Informal Language Learning (pp. 289-301). Wiley Blackwell. https://doi.org/10.1002/9781119472384.ch19 
Lee, J. S., \& Drajati, N. A. (2019). Affective variables and informal digital learning of English: Keys to willingness to communicate in a second language. Australasian Journal of Educational Technology, 35(5), 168-182. https://doi.org/10.14742/ajet.5177

Lee, J. S., \& Dressman, M. (2017). When IDLE hands make an English workshop: Informal digital learning of English and language proficiency. TESOL Quarterly, 52(2), 435-445. https://doi.org/10.1002/tesq.422

Lee, J. S., \& Lee, K. (2019). Informal digital learning of English and English as an international language: The path less traveled. British Journal of Educational Technology, 50(3), 1447-1461. https://doi.org/10.1111/bjet.12652

Lee, Y. J. \& Pass, C. (2014). Massively multiplayer online gaming and English language learning. In H. R. Gerber \& S. S. Abrams (Ed.), Bridging literacies with videogames. Sense Publishers.

Leppänen, S., \& Piirainen-Marsh, A. (2009). Language policy in the making: An analysis of bilingual gaming activities. Language Policy, 8(3), 261-284. https://doi.org/10.1007/s10993-009-9130-2

Li, Z., Chiu, C., \& Coady, M. R. (2014). The transformative power of gaming literacy: What can we learn from adolescent English language learners' literacy engagement in World of Warcraft (WoW)?. In H. R. Gerber \& S. S. Abrams (Ed.), Bridging literacies with videogames. Sense Publishers.

Pervolaraki, I. E., Garoufallou, E., Siatri, R., Zafeiriou, G., \& Virkus, S. (2015). Massively multiplayer online role playing games and digital information literacy. In S. Kurbanoglu, J. Boustany, S. Spiranec, E. Grassian, D. Mizrachi, L. Roy (Ed.). Information literacy: Moving toward sustainability (pp. 360-371). Springer.https://doi.org/10.1007/978-3-319-28197-1_37

Peterson, M. (2012a). Learner interaction in a massively multiplayer online role playing game (MMORPG): A sociocultural discourse analysis. ReCall, 24(3), 361-380. https://doi.org/10.1017/S0958344012000195

Peterson, M. (2012b). Language learner interaction in a massively multiplayer online role-playing game. In H. Reinders (Ed.). Digital Games in Language Learning and Teaching. New language and teaching environment (pp. 70-92). Palgrave Macmillan. https://doi.org/10.1057/9781137005267_5

Peterson, M. (2016). The use of massively multiplayer online role-playing games in CALL: An analysis of research, Computer Assisted Language Learning, 29(7), 1181-1194, https://doi.org/10.1080/09588221.2016.1197949 
Przymus, S. D. \& Smith, A. R. (2017). ¿Eres un Gamer?: Engaging transnational children in game-ecology language and identity socialization within the EFL environment. In J. Perren, K. Kelch, J. Byun, S. Cervantes, \& S. Safavi (Ed.), Application of CALL theory in ESL and EFL environments (pp. 269-290). International Genealogical Indix Global. https://doi.org/10.4018/978-15225-2933-0.ch015

Przymus, S. D., Lengeling, M. M., Mora-Pablo, I., \& Serna-Gutiérrez, O. (2020). From DACA to Dark Souls: MMORPGs as sanctuary, sites of language/ identity development, and third-space translanguaging pedagogy for Los Otros Dreamers. Journal of Language, Identity \& Education, $O(0), 1-17$. https://doi.org/10.1080/15348458.2020.1791711

Rahman, M.M., Singh, M.K.M., Johan, M. \& Ahmed, Z. (2020). English medium instruction ideology, management and practice: A case study of Bangladeshi private university. English Teaching \& Learning, 44, 61-79. https://doi.org/10.1007/s42321-019-00036-z

Rama, P. S., Black, R. W., van Es, E., \& Warschauer, M. (2012). Affordance for second language learning in World of Warcraft. ReCALL, 24(3), 322-338. https://doi.org/10.1017/S0958344012000171

Reinhardt, J. \& Sykes, J. M. (2014). Digital game and play activity in L2 teaching and learning. Language Learning and Technology, 18(2), 2-8.

Reinhardt, J., Warner, C., \& Lange, K. (2014). Digital games as practices and texts: New literacies and genres in an L2 German classroom. Digital literacies in foreign and second language education, 12, 159-177.

Skyes, J. M., Reinhardt, J., \& Thorne, S. L. (2010). Multiuser digital games as sites for research and practice. In Hult F. (Ed.), Directions and prospects for educational linguistics (pp. 117-135). Springer.

Spolsky, B. (2004). Language Policy. Cambridge University Press.

Spolsky, B. (2009). Language Management. Cambridge University Press.

Spolsky, B. (2012). What is language policy. In B. Spolsky (Ed.), The Cambridge Handbook of Language Policy (pp. 3-15). Cambridge University Press.

Toh, W. (2015). A multimodal discourse analysis of video games: A ludonarrative model (Doctoral dissertation). Retrieved from ProQuest Dissertation and Theses database. (No. 10754458)

Toh, W. (2019). A multimodal approach to video games and the player experiences. Routledge. 
Valencia, J. A. Á. (2015). Language views on social networking sites for language learning: the case of Busuu. Computer Assisted Language Learning, 29(5), 853-867. https://doi.org/10.1080/09588221.2015.1069361

$\mathrm{Wu}, \mathrm{M}$. (2019). The applications and effects of learning English through augmented reality: A case study of Pokémon Go. Computer Assisted Language Learning, $\quad 34(5-6)$, https://doi.org/10.1080/09588221.2019.1642211 778-812.

Zheng, D., Bischoff, M. \& Gilliland, B. (2015). Vocabulary learning in massively multiplayer online games: Context and action before words. Educational Technology Research and Development, 63(5). 771-790. https://doi.org/10.1007/s11423-015-9387-4 
This page has been intentionally left blank. 